especially in near testing, with the Maddox rod method do not in general agree with those obtained with the synoptophore.

Yours faithfully,

H. H. EMSLEY.

ALLIED INSTRUMENT MANUFACTURERS LTD.

20-24, PARKWAY, N.W.1.

March 13, 1947.

\title{
REMOVAL OF THE WRONG EYE
}

To the Editors of THE BRITISH JOURNAL OF OPHTHALMOLOGY.

DEAR SIRS, - I am grateful to Dr. Ascher for his letter on my paper on "Removal of the wrong eye." At the same time I do not follow his inference that the paper suggests that a case of this kind occurred in Elschnig's clinic either before or after 1908. Dr. Ascher's remarks about the meaning of "Soll" are, of course, correct, but seem to me to be irrelevant. I made no attempt at a literal translation as I thought that clumsy English would result and the free rendering I gave of the sentence in question conveys no implication of the kind Dr. Ascher indicates.

I have no information that such a case ever occurred in Elschnig's clinic but $I$ am assured that Elschnig used to impress the dangers of this accident on his students, which suggests that he had heard of at least one case. The significance of his foot-note is clear: it means that between writing his text and correcting the proofsotherwise why a foot-note?-he had learned of another case. I was careful to write "within his knowledge." The case may have occurred anywhere, possibly outside Austria altogether.

Cutting the eyelashes is only another method of marking the eye, though perhaps a better one than the use of adhesive plaster. The important point is that, for one reason or another, methods of marking the eye have proved unreliable.

I have for many years given up cutting the lashes in eye operations except sometimes a few at the lateral and medial ends of the upper lid. I doubt whether any advantage is gained by cutting even these.

Yours faithfully,

H. M. TRAQUAIR.

16, MANOR PLACE,

EDINBURGH, 3.

April 10, 1947. 